\title{
Diabetes Mellitus in Elderly Patients
}

\author{
Anis Mzabi ${ }^{1}$, Hend Zorgati ${ }^{1}$, Maissa Thabet ${ }^{2 *}$, Jihed Anoun ${ }^{1}$, Imen Ben Hassine ${ }^{1}$, Fatma Ben Fredj ${ }^{1}$, Karmeni \\ Monia $^{1}$ and Chadia Laouani ${ }^{1}$ \\ ${ }^{1}$ Internal Medicine Department, University of Sousse, Tunisia \\ ${ }^{2}$ Endocrinology Department and Faculty of medicine of Sousse, University of Sousse, Tunisia
}

Submission: March 20, 2021; Published: April 08, 2021

*Corresponding author: Maissa Thabet, Endocrinology Department \& Faculty of Medicine of Sousse, Farhat Hached Hospital, University of Sousse 400 , Sousse, Tunisia

Abstrcat

Background: Diabetes mellitus, a chronic metabolic disease, is considerably increasing among elderly patients. It is associated with significant morbidity and mortality especially in these patients who usually had many comorbidity.

Aim: The aim was to describe the clinical characteristics and complications in elderly patient with diabetes mellitus (DM).

Methods: A retrospective single-center study performed in the internal medicine department at a teaching hospital of Sahloul, Tunisia between 2005 and 2014 and 338 elderly patients (>=65 years according to WHO) were enrolled. Information's regarding demographic and clinical characteristics were obtained from medical files.

Results: Three-hundred thirty-eight old patients were diabetics. The mean age was 73 years old. All of them had type 2 diabetes mellitus. Obesity was observed in 55 (16.2\%) patients. Acute metabolic complications were found in 47 patients; ketosis in 34 patients, hyperosmolar in 10 patients and hypoglycemia in 3 patients. Twenty-five (24\%) patients were smoker. Diabetes was complicated by neuropathy in 58 (17.1\%) patients, retinopathy in $32(9.4 \%)$ patients, nephropathy in 77 (22.7\%) patients, acute ischemic stroke in 58 (17.1\%) patients, limb arteritis in 40 $(11.8 \%)$ patients and ischemic heart disease in $61(18.04 \%)$ patients. The lipid abnormalities were: hypercholesterolemia 8 (2.3\%), hypo HDL, cholesterol 114 cases (33.7\%) and hypertriglyceridemia 69 (20.4\%).

Conclusion: Diabetes mellitus is very common in elderly patients. Given the high risk and complications of diabetes in these patients, a regular follow-up and early screening is required.

Keywords: Diabetes mellitus; Elderly; Chronic metabolic disorder; Fasting glycaemia

\section{Introduction}

Diabetes mellitus (DM) is a common and chronic metabolic disorder defined as a fasting glycaemia $\geq 1.26 \mathrm{~g} / \mathrm{l}(7.0 \mathrm{mmol} / \mathrm{L})$ or post-meal glycemia (75 g) $\geq 2 \mathrm{~g} / \mathrm{l}$ (11.11 mmol/L) [1]. Because of long life expectancy and life style changes, aging population (aged 65 years and over according to World Health Organization (WHO)) will increase substantially from 524 million in 2010 to 1.5 trillion in 2050 [2,3]. Elderly people are a risk factor of DM with an important morbidity and mortality [4]. Despite different treatments, patients with DM still have poor outcomes. The current study determines the clinical characteristics and complications in DM 'patients aged 65 years and more admitted in internal medicine department at Sahloul hospital in order to greater understanding geriatric diabetes and to prevent poor outcomes.

\section{Methods}

A retrospective single-center study performed in the internal medicine department at a teaching hospital of Sahloul, Tunisia between 2005 and 2014 and 338 elderly patients (>=65 years according to WHO) were enrolled. Information's regarding demographic and clinical characteristics were obtained from medical files.

\section{Results}

Three-hundred thirty-eight old patients were diabetics. The mean age was 73 years old. All of them had type 2 diabetes mellitus. Obesity was observed in $55(16.2 \%)$ patients. Acute metabolic complications were found in 47 patients; ketosis in 
34 patients, hyperosmolar in 10 patients and hypoglycemia in 3 patients. Twenty-five $(24 \%)$ patients were smoker. Diabetes was complicated by neuropathy in $58(17.1 \%)$ patients, retinopathy in $32(9.4 \%)$ patients, nephropathy in 77 (22.7\%) patients, acute ischemic stroke in $58(17.1 \%)$ patients, limb arteritis in $40(11.8 \%)$ patients and ischemic heart disease in $61(18.04 \%)$ patients. The lipid abnormalities were hypercholesterolemia 8 (2.3\%), hypoHDL, cholesterol 114 cases (33.7\%) and hypertriglyceridemia 69 (20.4\%).

\section{Discussion}

In this retrospective study, most of elderly patients had macro vascular and/or micro vascular complications. It was mainly ischemic heart disease $(22.7 \%)$ and chronic renal failure (18.04\%) followed by neuropathy $(17.1 \%)$ and acute ischemic stroke (17.1\%). The type 2 diabetes is serious healthcare problem in Tunisia and worldwide. It is the most prevalent form reported in old patients. In the United States, diagnosed DM or undiagnosed affected 10.9 million old patients in 2010 and it expected to reach 26.7 million by $2050,55 \%$ of all diabetes case [5]. In Tunisia, the prevalence of type 2 of DM in Tunisia in 1997 was $13.1 \%$ and it will increase with age, except for men aged between 65 and 74 years [6]. According to Leibson CL et al. [7] DM increased in old patients, but this incidence declined in very old age.

The physiopathology of DM was explained by insulin resistance and deficiency of insulin secretion from $\beta$-cells associated with genetic factors and lifestyle factors [8-10]. In a study conducted by Setyawati et al. [11] obesity and genetic factors were independently associated with DM in old patients. Other research showed that BMI was inversely related to age $[12,13]$. In this study, 55 (16.2\%) patients had obesity and more than a half (56.5\%) had lipid abnormalities. Obesity is common in diabetes patients and it is also a risk factor for cardiovascular disease and lead to an increase of using antihypertensive and lipid lowering drugs [14]. In a multicenter study carried out in the United States between 1994 and 2004, the rates of cerebrovascular, renal, and lower extremity complications increased over year in diabetes old patients compared with the control group, the cardiovascular complication increased only the first year and only ophthalmic complications decreased during the follow-up period [15]. In the current study, elderly patients had micro vascular and macro vascular complication. Ischemic heart disease and chronic renal failure followed by neuropathy and acute ischemic stroke were the most prevalent complication that has been reported. Maoui A et al. [10] reported that neuropathy and retinopathy were the main complications affecting the Tunisian diabetic patient. According to Angelyn Bethel $\mathrm{M}$ et al. the cardiovascular disease was an important risk factor in elderly patients newly diagnosed with DM leading to an important morbidity and $57.6 \%$ of the DM group had heart failure. Chronic renal failure also increases in those patients [16]. In a large cohort study, conducted in California, age and duration of diabetes were independently associated with poor outcomes and cardiovascular disease and hypoglycemia were the most common complications. Within specific age groups, hypoglycemia and micro vascular complications, increased with longer duration [4]. In this study, 3 patients (2.88\%) presented hypoglycemia during their hospitalization but it could be underestimated. Hypoglycemia could be related to a dysregulation or unawareness and cognitive or impairment in aging patients. The use of some intensive treatments (insulin...) also could be associated with a high risk of hypoglycemia.

The management of diabetes in older patients usually based on glycemic control and glycated hemoglobin or HbA1C (A1C) at $7.0 \%$ which could reduce micro vascular complications and long-term cardiovascular disorder in adult patients $[17,18]$. In a randomized, controlled, multicenter, prospective Japanese study, an intensive blood-glucose control in patients with type $2 \mathrm{DM}$, decreased the risk of micro vascular complications, but not macro vascular disease [17]. Different treatments could be proposed to elderly patients while respecting the contraindications. In old patients with mild or moderate level of glycemia oral hypoglycaemic agents might be effective [19]. The guidelines of ADA recommended the use of metformin as a first-line treatment for older patients with type 2 of diabetes except contraindications and they recommended an association with other oral antidiabetic agents or insulin if the monotherapy with metformin couldn't be sufficient for the control of blood glucose [20]. Elderly patients with type 2 diabetes, require a follow-up program is in order to reduce fatal outcomes or complications that alter their quality of life. However, prevention including nutritional, physical activity is an essential element to reduce the rate of DM in elderly patients and a preventives strategies should be implemented.

\section{Conclusion}

DM in elderly patients is a serious and alarming healthcare problem. It is associated with an important morbidity and a social and economic burden. The current study emphasizes the different complications associated with DM in old patients. A regular follow-up and early screening is required. Moreover, preventives measures are necessary in order to reduce DM in those patients and its complications and to improve their quality of life.

\section{References}

1. Chentli F, Azzoug S, Mahgoun S (2015) Diabetes mellitus in elderly. Indian J Endocrinol Metab 19(6): 744-752.

2. Garland A, Olafson K, Ramsey CD, Yogendran M, Fransoo R (2013) Epidemiology of critically ill patients in intensive care units: a population-based observational study. Crit Care 17(5): R212.

3. Current and Projected Workforce Requirements for Care of the Critically Ill and Patients with Pulmonary Disease can we Meet the Requirements of an Aging Population?

4. Huang ES, Laiteerapong N, Liu JY, John PM, Moffet HH, et al. (2014) Rates of Complications and Mortality in Older Diabetes Patients: The Diabetes and Aging Study. JAMA Intern Med 174(2): 251-258.

5. Caspersen CJ, Thomas GD, Boseman LA, Beckles GLA, Albright AL (2012) Aging, Diabetes, and the Public Health System in the United States. Am J Public Health 102(8): 1482-1497. 
6. Saidi O, O Flaherty M, Mansour NB, Aissi W, Lassoued O, et al. (2015) Forecasting Tunisian type 2 diabetes prevalence to 2027: validation of a simple model. BMC Public Health 15(1):104.

7. Cl L, Pc O, E A, Pj P, Lj M (1997) Relative contributions of incidence and survival to increasing prevalence of adult-onset diabetes mellitus: a population-based study. Am J Epidemiol 146(1): 12-22.

8. Lee PG, Halter JB (2017) The Pathophysiology of Hyperglycemia in Older Adults: Clinical Considerations. Diabetes Care 40(4): 444-52.

9. Mozaffarian D, Kamineni A, Carnethon M, Djoussé L, Mukamal KJ, et al. (2009) Lifestyle Risk Factors and New-Onset Diabetes Mellitus in Older Adults. Arch Intern Med 169(8): 798-807.

10. Diabetes Mellitus Type 2; Epidemiology Prevalence; Risk Factors ; Prevention; Review; Tunisia.

11. Setyawati AD, Ngo T hai L, Padila P, Andri J (2020) Obesity and Heredity for Diabetes Mellitus among Elderly. JOSING J Nurs Health 1(1): 26-31.

12. La V, Á R, J S, Jf A, H P et al. (2014) Relationships between obesity, glycemic control, and cardiovascular risk factors: a pooled analysis of cross-sectional data from Spanish patients with type 2 diabetes in the preinsulin stage. BMC Cardiovasc Disord 14: 153.

13. H S, H I, Y O, Y A, N Y (2003) Obesity and type 2 diabetes in Japanese patients. Lancet Lond Engl 361(9351): 85.
14. I M, A K, K M, M O, T N, et al. (2018) Twelve-year trends of increasing overweight and obesity in patients with diabetes: the Shiga Diabetes Clinical Survey. Endocr J 65(5): 527-536.

15. Fa S, Ma B, D R, Am S, Mn F (2008) The growing burden of diabetes mellitus in the US elderly population. Arch Intern Med 168(2): 192199.

16. Ma B, Fa S, D B, Mn F (2007) Longitudinal incidence and prevalence of adverse outcomes of diabetes mellitus in elderly patients. Arch Intern Med 167(9): 921-927.

17. (1998) Intensive blood-glucose control with sulphonylureas or insulin compared with conventional treatment and risk of complications in patients with type 2 diabetes (UKPDS 33). UK Prospective Diabetes Study (UKPDS) Group. Lancet Lond Engl [Internet] 352(9131): $837-$ 853.

18. Holman RR, Paul SK, Bethel MA, Matthews DR, Neil HAW (2009) 10Year Follow-up of Intensive Glucose Control in Type 2 Diabetes.

19. Y W, Mz Q, Q L, Q L, Zw C (2010) Clinical analysis of elderly patients with elderly-onset type 2 diabetes mellitus in China: assessment of appropriate therapy. J Int Med Res 38(3): 1134-1141.

20. (2019) Association AD. 12. Older Adults: Standards of Medical Care in Diabetes-2019. Diabetes Care 1: 42(Suppl 1): S139-47.

Your next submission with Juniper Publishers will reach you the below assets

- Quality Editorial service

- Swift Peer Review

- Reprints availability

- E-prints Service

- Manuscript Podcast for convenient understanding

- Global attainment for your research

- Manuscript accessibility in different formats

( Pdf, E-pub, Full Text, Audio)

- Unceasing customer service

Track the below URL for one-step submission https://juniperpublishers.com/online-submission.php 